\title{
Membership of the ICSB Subcommittee on the Taxonomy of the Actinomycetales
}

November 1976

E. Küster, Chairman

Institut für landwirtschaftliche Mikrobiologie

Justus Liebig Universität

Landgraf Philip Platz 4

63 Giessen, Federal Republic of Germany

S. T. Williams, Secretary

Department of Botany

Liverpool University

Liverpool, L69 3BX

United Kingdom

T. Arai

Department of Antibiotics

Research Institute for Chemo-biodynamics

Chiba University

Izumi-cho

Marashino

Chiba, Japan

E. Baldacci

Instituto di Patologia Vegetale

Via Celoria 2

20133 Milan, Italy

S. G. Bradley

Department of Microbiology

Medical College of Virginia

Richmond, Virginia 23219, USA

T. Cross

Postgraduate School of Biological Science

University of Bradford

Bradford

Yorks, BD7 1DP, United Kingdom

G. A. De Vries

Centraalbureau voor Schimmelcultures

OOsterstraat 1

Baarn, Netherlands

D. Gottlieb

Department of Plant Pathology

College of Agriculture

University of Illinois

10 Hort. Field Lab.

Urbana, Illinois 61801, USA

L. V. Kalakoutskii

Institute Biochemistry and Physiology of Microorganisms
USSR Academy of Sciences

Pustchino on the Oka

Moscow Region, USSR

W. Kurylowicz

State Institute of Hygiene

Chockimska St.

Warsaw, Poland

R. Locei

Instituto di Patologia Vegetale

Mycological Lab.

Via Celoria 2

20133 Milan, Italy

Y. Okami

Institute of Microbial Chemistry

3-4-23 Kami-Osaki

Shinagawa-ku

Tokyo, Japan

H. Prauser

Institut für Mikrobiologie und Experimentelle

Therapie

Beuthenbergstrasse 11

69 Jena, German Democratic Republic

T. G. Pridham

ARS Culture Collection

Res. Ferm. Lab.

U.S. Department of Agriculture

NRRL,

1815 University St.

Peoria, Illinois 61604, USA

T. P. Preobrashenskaja

Institute of New Antibiotics

Academy of Medical Sciences

Bolskaja Pirogovskaja 11

Moscow, USSR

E. B. Shirling

Department of Botany and Bacteriology

Ohio Wesleyan University

Delaware, Ohio 43015, USA

Z. Tesic

Institute of Microbiology

Faculty of Agriculture

University of Beograd

Nemanjina 6

Belgrade-Zemun, Yugoslavia 